\title{
Virtual Reality in Pediatric Neurorehabilitation: Attention Deficit Hyperactivity Disorder, Autism and Cerebral Palsy
}

\author{
Michelle Wang Denise Reid \\ Virtual Reality and Neurorehabilitation Laboratory, Department of Rehabilitation Science, University of Toronto, \\ Toronto, Ont., Canada
}

\section{Key Words}

Virtual reality $\cdot$ Children $\cdot$ Rehabilitation - Cerebral palsy $\cdot$ Attention deficit hyperactivity disorder $\cdot$ Autism

\begin{abstract}
This paper presents the current status and use of virtual reality (VR) for children with attention deficit hyperactivity disorder (ADHD), autism and cerebral palsy. This literature review explores how VR systems have been used as treatment tools to address the primary impairments of these disorders. Three major classes of VR display systems are identified that can be characterized by the type of human-computer interaction provided: (1) feedback-focused interaction, (2) gesture-based interaction, and (3) haptic-based interaction. The demonstrated effectiveness and potential effectiveness of each class are discussed in the context of remediating the primary impairments of children with ADHD, autism and cerebral palsy. Three major themes for future research are discussed to support continued research interest in using VR in pediatric neurorehabilitation. Copyright $\odot 2010$ S. Karger AG, Basel
\end{abstract}

\section{Introduction}

This paper presents the current status and use of virtual reality (VR) for children with specific neurodevelopmental disorders. Neurodevelopmental disorders encompass a wide range of diagnoses including Down's syndrome, spina bifida, epilepsy, attention deficit hyperactivity disorder (ADHD), autism and cerebral palsy [1]. This literature review focuses on three specific disorders: ADHD, autism and cerebral palsy. In the past decade, VR has been used increasingly as a treatment tool for these pediatric populations $[2,3]$. Because children with these disorders are diagnosed and treated based on overt physical criteria, either behavioral or motor patterns, they are particularly appropriate for VR interventions. VR interventions naturally facilitate specific action-based responses to events occurring in the virtual environment (VE). This literature review focuses on the types of VR systems that are used as treatment tools to address the primary impairments of children with ADHD, autism and cerebral palsy.

The primary deficits of ADHD include the presence and frequency of inattentive, impulsive and hyperactive behaviors [4]. For autism, the key impairments include the absence of typical social and communication behaviors, the lack of imagination or abstract thought, and the

\section{KARGER \\ Fax +4161306 1234 E-Mail karger@karger.ch} www.karger.com
Virtual Reality and Neurorehabilitation Laboratory

Department of Rehabilitation Science, University of Toronto

160-500 University Avenue, Toronto, ON M5G 1V7 (Canada)

Tel. +1 416978 1250, Fax +1 416946 8762, E-Mail mwang@ qmed.ca 
presence of stereotyped, repetitive behaviors [4]. The deficits in cerebral palsy are primarily motor deficits, affecting upper- and lower-limb function and postural control to varying degrees [5]. Focusing on recent research using $\mathrm{VR}$ as a treatment tool for children with ADHD, autism and cerebral palsy, a literature search was conducted using the following databases: Scholar's Portal, Medline, Embase, AMED, Cinahl, IEEE, Biosis, Scopus, and Web of Science. In addition to variations of the names of the disorders, the key words included combinations of: child, children, pediatric, paediatric, virtual reality and interactive technology.

The reference lists of review articles and all primary sources were also reviewed for relevant studies. The inclusion criteria for a study were as follows: (1) the publication year was between 2000 and the present; (2) the study used VR as a treatment tool, not as an assessment or entertainment system; (3) the study focused on remediating the primary deficits of ADHD, autism or cerebral palsy, which are those deficits that comprise the diagnostic criteria of each disorder (DSM-IV-TR or ICD-10); (4) the study participants were children (ages 18 and under), and (5) the article was published in a peer-reviewed journal or peer-edited conference proceedings book, and presented original work. A total of 20 articles were identified: 4 for ADHD, 3 for autism and 13 for cerebral palsy. This paper begins by discussing the overall benefits of VR in the context of pediatric rehabilitation, and then focuses on synthesizing the findings of the 20 studies identified.

\section{VR in Pediatric Rehabilitation}

VR is a simulation of the real world using computer graphics. Defining features of a VR program or application include interaction and immersion. Human-computer interactivity is achieved through multiple sensory channels that allow children to explore VEs through sight, sound, touch and sometimes even smell $[6,7]$. Immersion is considered the degree to which the child feels engrossed or enveloped within the VE [8]. Together, the level of immersion and interaction are key factors in establishing the degree of presence, which is the feeling of 'being there' in the VE. A higher degree of presence is associated with greater engagement, which has been linked to better treatment outcomes [9]. A comprehensive discussion of the components and importance of presence is beyond the scope of this review; the reader is referred to Witmer et al. [8], Witmer and Singer [10], Slater et al. [11] and Sacau et al. [12] for more detailed discussions on presence. Using VR as an educational and therapeutic tool allows instructors and therapists to offer both flexibility and control when administering treatments, increasing the probability of skill transfer and ensuring safety during learning.

Flexibility is essential when designing therapeutic programs because children with neurodevelopmental disorders are not only heterogeneous, but also require extra learning supports. Due to the heterogeneity of these disorders, one predefined intervention cannot possibly address the needs of all these children [13-16]. VR adds the flexibility required to individualize the activity for each child or subgroup of children. Individualization of the VR intervention can be achieved by integrating the child's own interests and preferences into the program, by modifying the complexity of the VE to increase attention and minimize distractions, and finally, by exaggerating the effect of feedback to maximize its impact on the child. These techniques maximize engagement, which is one of the strongest predictors of successful learning [1719]. In occupational therapy, engagement in VR has been shown to maximize occupational engagement successfully [9].

While flexibility is useful to individualize the program, having control over the design of the VR program facilitates the incorporation of structured and systematic teaching strategies. Children with disabilities require additional supports to help them anticipate events and understand what behaviors are expected of them [20]. Additional structures such as instructions, cues, prompts and feedback are easily integrated into each stage of the VR task. In addition, control of the VR program allows systematic administration of, and incremental progression through, the exercises. As both cognitive and physical interventions typically require intense repetition $[2$, $21,22]$, VR can lessen the burden on the instructor by presenting exercises in a consistent and predictable manner while maintaining the child's attention and engagement.

Having both flexibility and control of the VR program helps instructors and therapists to address two key concerns of pediatric treatment programs. The first is the problem of generalization, or the transfer of newly learned skills to new environments [23-26]. This is the most challenging outcome of treatment; therefore, incorporating specific strategies to maximize generalization is a significant part of intervention planning. Because VR applications are fundamentally designed to simulate real-life situations, there is a high degree of ecological validity: the degree to which the VE simulates the real environment 
[27]. High ecological validity increases the probability that skills learned in the simulated environment will transfer or generalize to the real world [27]. Thus, creating a variety of well-controlled VEs, each designed to incorporate natural stimuli, cues and feedback, is an intuitively effective approach to facilitate generalization.

Safety is the second major challenge of pediatric rehabilitation. Safety is one of the top concerns of parents of children with disabilities because children with disabilities may not have developed the adequate cognitive skills to understand the concept of danger, or the adequate physical skills to avoid dangerous situations. VR offers safe access to realistic environments that would be considered dangerous in the real world [28, 29]. In a study by Miller and Reid [9], children with cerebral palsy who played virtual sports games commented on the safety aspect of this type of play engagement; 'Every time the ball hits me when I'm playing in not VR, I usually got hurt. Luckily I didn't hurt my head after the ball went on my head. There's a lot of balls shooting at a fast speed and I don't get hurt' [9]. The development of confidence, selfefficacy, and requisite skills in a safe, nonjudgmental environment better prepares the child to approach the task in the real world [30].

Overall, VR systems provide the instructor or therapist with a balance between flexibility and control of the treatment program. The realism of the simulated environment allows the child to learn important skills in a safe environment and increases the probability that these skills will be transferred into their everyday lives. Both the degree of immersion and level of interaction have an impact on the realism and ecological validity achieved by the program. Head-mounted devices (HMDs) have been considered the gold standard for fully, immersive, 3D VR systems [2]. Typically, HMDs require the child to wear helmet-like equipment which immerses him or her completely into the VE and blocks out extraneous sights and sounds from the real environment. However, the costs associated with developing HMD systems, as well as the associated side effects (i.e. cybersickness) and cumbersome nature of using HMDs, have led to a surge of nonHMD systems in the field of rehabilitation. While nonHMD, 2D flatscreen systems do not offer the same degree of immersion, technological advances have facilitated greater on-screen visual resolution, thus increasing immersion and interaction without full 3D capabilities. In this paper, attention is diverted from the traditional division between HMD and non-HMD devices, to the types of interaction afforded by the display devices of different VR systems. Three major classes of display interfaces were identified that can be characterized by the type of human-computer interaction provided: (1) feedback-focused interaction, (2) gesture-based interaction, and (3) haptic-based interaction. The demonstrated effectiveness and potential effectiveness of each class will be discussed in the context of remediating the primary impairments of children with ADHD, autism and cerebral palsy. The studies [31-51] are summarized in table 1.

\section{VR Systems with Feedback-Focused Interaction}

VR is often used as an adjunct to a well-established, dominant mode of therapy. In these systems, VR is used as the medium through which feedback or reinforcement is provided, rather than as the primary treatment tool itself. The child is required to make gains in the non-VR, dominant form of therapy in order to benefit from interaction and feedback from the VE. Although this type of human-computer interaction is typically $1 \mathrm{D}$ and varies only quantitatively, the child still retains real-time control over the events occurring in the VE. Feedback-focused systems capitalize on the ability of VR programs to increase engagement and motivation by integrating a child's preferred interests into the program.

One type of feedback-focused system integrates VR with neurofeedback training. Neurofeedback, or electroencephalography (EEG) biofeedback is an empirically validated procedure used mainly for children with ADHD to increase attention and decrease hyperactivity and impulsivity. This procedure uses electrical signals that are generated by the active brain, which can be localized, measured and monitored through externally placed electrodes on the child's skull. The patterns of EEG signals, represented by the frequency and amplitude of the signals, indicate the state of arousal of the brain $[32,33]$. The EEG patterns of children with ADHD differ from those of typical children and are closely associated with decreases in attention and inhibition [32]. The goal of EEG biofeedback therapy is to teach the child to regulate and normalize his or her own EEG patterns by offering reinforcement when target patterns are achieved [14]. VR has recently been integrated as a tool to provide this reinforcement.

Cho et al. [32] reported the use of neurofeedback with 28 juvenile offenders who did not have formal ADHD diagnoses, but who were reported to have problems of attention, impulsivity, hyperactivity and distractibility. The participants were divided into 3 groups: biofeedback with VR, biofeedback only, and control (no treatment). 
Table 1. Summary of studies included in this review

\begin{tabular}{|c|c|c|c|c|}
\hline Source & \multicolumn{2}{|c|}{ Participant characteristics } & Description of treatment & Description of results \\
\hline \multicolumn{5}{|c|}{ Studies with children with ADHD } \\
\hline $\begin{array}{l}\text { Cho } \\
\text { et al. [31] }\end{array}$ & $\begin{array}{l}\text { Gender } \\
\text { Mean age }\end{array}$ & $\begin{array}{l}\text { VR group }(\mathrm{n}=8) \\
\text { Non-VR group }(\mathrm{n}=9) \\
\text { Control group }(\mathrm{n}=9) \\
\text { Not indicated } \\
\text { VR group (13 years) } \\
\text { Non-VR group }(15.11 \text { years }) \\
\text { Control group }(14.67 \text { years) } \\
\text { All with learning difficulties } \\
\text { with symptoms of inattention, } \\
\text { impulsivity and hyperactivity; } \\
\text { no formal diagnosis of ADHD }\end{array}$ & $\begin{array}{l}\text { Design: } \\
\text { Between groups, randomization to } 3 \text { groups } \\
\text { VR system: } \\
\text { HMD or desktop display } \\
\text { Intervention: } \\
\text { Virtual classroom with } 2 \text { tasks: virtual reality } \\
\text { comparison training task and virtual reality } \\
\text { sustained attention training task } \\
\text { Treatment intensity: } \\
8 \times 20 \text {-min sessions, } 2 \text { weeks }\end{array}$ & $\begin{array}{l}\text { (1) VR group earned higher scores on VR task than } \\
\text { non-VR group, but difference was not significant } \\
\text { (2) CPT: VR group improved significantly on } \\
\text { response accuracy, perceptual sensitivity and } \\
\text { response bias, as compared to non-VR and } \\
\text { control groups. No significant improvements } \\
\text { on other CPT measures }\end{array}$ \\
\hline $\begin{array}{l}\text { Cho } \\
\text { et al. [32] }\end{array}$ & $\begin{array}{l}\text { Gender } \\
\text { Age range } \\
\text { Diagnosis }\end{array}$ & $\begin{array}{l}\text { VR group }(\mathrm{n}=10) \\
\text { Non-VR group }(\mathrm{n}=9) \\
\text { Control group }(\mathrm{n}=9) \\
\text { All male } \\
14-18 \text { years } \\
\text { All with learning difficulties } \\
\text { with symptoms of inattention, } \\
\text { impulsivity and hyperactivity; } \\
\text { no formal diagnosis of ADHD }\end{array}$ & $\begin{array}{l}\text { Design: } \\
\text { Between groups, } \\
\text { randomization to } 3 \text { groups } \\
\text { VR system: } \\
\text { HMD or desktop display with neurofeedback } \\
\text { Intervention: } \\
\text { Neurofeedback with integrated VR feedback to } \\
\text { increase target EEG signal } \\
\text { Treatment intensity: } \\
8 \times 20 \text {-min sessions, } 2 \text { weeks }\end{array}$ & $\begin{array}{l}\text { (1) Greater improvements on completion time in VR } \\
\text { group than in non-VR group. VR group had } \\
\text { significantly higher target EEG wave ratio rates } \\
\text { than non-VR group } \\
\text { (2) CPT: VR and non-VR group improved on } \\
\text { number of hits, commission errors and response } \\
\text { bias (nonsignificant). All groups improved on } \\
\text { perceptual sensitivity (nonsignificant). VR group } \\
\text { improved significantly on reaction time }\end{array}$ \\
\hline $\begin{array}{l}\text { Othmer } \\
\text { et al. [33] }\end{array}$ & $\begin{array}{l}\text { Sample size } \\
\text { Gender } \\
\text { Mean age } \\
\text { Diagnosis }\end{array}$ & $\begin{array}{l}\mathrm{n}=46 \\
\text { Not indicated } \\
\text { Not indicated } \\
\text { ADHD, epilepsy or mood dis- } \\
\text { orders }\end{array}$ & $\begin{array}{l}\text { Design: } \\
\text { Between groups, not randomized } \\
\text { VR system: } \\
\text { Desktop display with neurofeedback } \\
\text { Intervention: } \\
\text { Neurofeedback with integrated VR feedback to } \\
\text { increase target EEG signal } \\
\text { Treatment intensity: } \\
20 \times 30 \text {-min sessions }\end{array}$ & $\begin{array}{l}\text { (1) Symbol Digit Modality test: 3D group improved } \\
\text { significantly more than 2D group } \\
\text { (2) Word fluency test: 3D group improved more than } \\
\text { 2D group (marginal significance) } \\
\text { (3) Impulse control test: 3D group improved more } \\
\text { than 2D group (marginal significance) } \\
\text { (4) Number of sessions completed: 3D group } \\
\text { completed more sessions than 2D group } \\
\text { (marginal significance) }\end{array}$ \\
\hline $\begin{array}{l}\text { Yan } \\
\text { et al. [34] }\end{array}$ & $\begin{array}{l}\text { Sample size } \\
\text { Gender } \\
\text { Age range } \\
\text { Diagnosis }\end{array}$ & $\begin{array}{l}\mathrm{n}=12 \\
10 \text { males, } 2 \text { females } \\
8-12 \text { years } \\
\text { ADHD }\end{array}$ & $\begin{array}{l}\text { Design: } \\
\text { Within group } \\
\text { VR system: } \\
\text { Desktop display with neurofeedback } \\
\text { Intervention: } \\
\text { Neurofeedback with integrated VR feedback to } \\
\text { increase target EEG signal } \\
\text { Treatment intensity: } \\
2 \times 25 \text { - to } 35 \text {-min sessions per week, } 10 \text { weeks }\end{array}$ & $\begin{array}{l}\text { (1) IVA-CPT: significant improvements on both } \\
\text { RCQ (impulsivity) and AQ (inattentiveness) } \\
\text { measures }\end{array}$ \\
\hline \multicolumn{5}{|c|}{ Studies with children with autism } \\
\hline $\begin{array}{l}\text { Baum- } \\
\text { inger } \\
\text { et al. [35] }\end{array}$ & $\begin{array}{l}\text { Sample size } \\
\text { Gender } \\
\text { Age range } \\
\text { Diagnosis }\end{array}$ & $\begin{array}{l}\mathrm{n}=6 \text { ( } 3 \text { dyads) } \\
\text { Not indicated } \\
9-11 \text { years } \\
\text { High functioning autism }\end{array}$ & $\begin{array}{l}\text { Design: } \\
\text { A-B-A Desi } \\
\text { VR System: } \\
\text { DiamondTouch with StoryTable } \\
\text { Intervention: } \\
\text { StoryTable training to teach joint social behaviors } \\
\text { and communication } \\
\text { Treatment intensity: } \\
\text { 10× } 20 \text {-min sessions, } 3-4 \text { times for } 3 \text { weeks }\end{array}$ & $\begin{array}{l}\text { (1) StoryTable performance: increase in positive } \\
\text { social behaviors and decrease in stereotypic, } \\
\text { repetitive behaviors } \\
\text { (2) MarbleWorks performance: increase in positive } \\
\text { social behaviors, complex play, and narrative } \\
\text { utterances }\end{array}$ \\
\hline $\begin{array}{l}\text { Herrera } \\
\text { et al. [36] }\end{array}$ & $\begin{array}{l}\text { Sample size } \\
\text { Gender } \\
\text { Age } \\
\text { Diagnosis }\end{array}$ & $\begin{array}{l}\mathrm{n}=2 \\
\text { Both male } \\
8 ; 6 \text { and } 15 ; 7 \\
\text { Autism spectrum disorder }\end{array}$ & $\begin{array}{l}\text { Design: } \\
\text { Within subjects } \\
\text { VR System: } \\
\text { Touchscreen } \\
\text { Intervention: } \\
\text { Virtual supermarket, 'I am going to act as if ...' } \\
\text { tool to teach imagination } \\
\text { Treatment intensity: } \\
28 \times 20 \text { - to } 30 \text {-min sessions, approx. } 3 \text { sessions per } \\
\text { week }\end{array}$ & $\begin{array}{l}\text { (1) Functional use of objects: both children improved } \\
\text { (2) Symbolic Play Test: one child improved } \\
\text { (3) Test of Pretend Play: both children improved in } \\
\text { structured and unstructured scenarios and in a } \\
\text { number of free play samples } \\
\text { (4) Imagination Understanding: both children } \\
\text { improved } \\
\text { (5) Magic Understanding: both children improved }\end{array}$ \\
\hline
\end{tabular}


Table 1 (continued)

\begin{tabular}{|c|c|c|c|c|}
\hline Source & Participant c & haracteristics & Description of treatment & Description of results \\
\hline $\begin{array}{l}\text { Mitchell } \\
\text { et al. [37] }\end{array}$ & $\begin{array}{l}\text { Sample size } \\
\text { Gender } \\
\text { Mean age } \\
\text { Diagnosis }\end{array}$ & $\begin{array}{l}\mathrm{n}=7 \text { ( } 1 \text { withdrawal }) \\
4 \text { males, } 3 \text { females } \\
15 \text { years } \\
\text { Autism spectrum disorder }\end{array}$ & $\begin{array}{l}\text { Design: } \\
\text { Within subjects } \\
\text { VR system: } \\
\text { Desktop display with mouse } \\
\text { Intervention: } \\
\text { Virtual café to teach social understanding } \\
\text { Treatment intensity: } \\
2 \times 30 \text { - to } 50 \text {-min sessions, successive days }\end{array}$ & $\begin{array}{l}\text { (1) Ratings of choice about where to sit: } 4 \text { of } 6 \\
\text { participants improved significantly on at least } \\
1 \text { video scene (café or bus) after VR exposure } \\
\text { (2) Ratings of reasoning about where to sit: all } \\
\text { improved significantly on reasoning about where } \\
\text { to sit on at least } 1 \text { video scene (café or bus). } \\
\text { Significantly more gains after VR than after } \\
\text { no VR }\end{array}$ \\
\hline
\end{tabular}

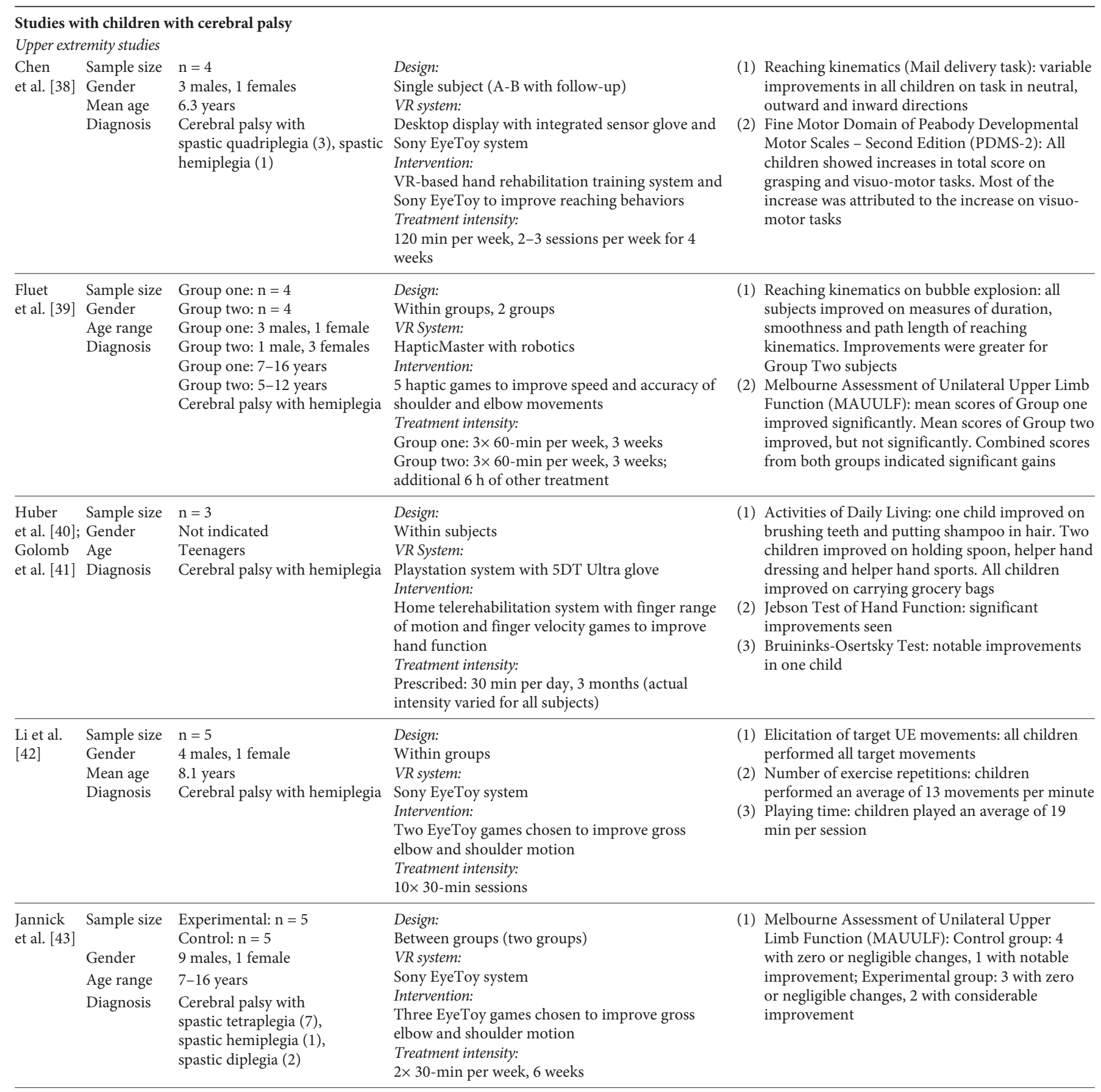


Table 1 (continued)

\begin{tabular}{|c|c|c|c|c|}
\hline Source & Participant c & haracteristics & Description of treatment & Description of results \\
\hline $\begin{array}{l}\text { Odle } \\
\text { et al. [44] }\end{array}$ & $\begin{array}{l}\text { Sample size } \\
\text { Gender } \\
\text { Age } \\
\text { Diagnosis }\end{array}$ & $\begin{array}{l}\mathrm{n}=3 \\
\text { All male } \\
4,10 \text { and } 12 \text { years } \\
\text { Cerebral palsy with hemiplegia } \\
\text { (1), spastic diplegia (1), diple- } \\
\text { gia (1) }\end{array}$ & $\begin{array}{l}\text { Design: } \\
\text { Within subjects } \\
\text { VR system: } \\
\text { Hands-Up System } \\
\text { Intervention: } \\
\text { Customized games to improve upper extremity } \\
\text { movement } \\
\text { Treatment intensity: } \\
\text { 1×60-min per week, } 5 \text { weeks }\end{array}$ & $\begin{array}{l}\text { (1) Velcro task: all improved } \\
\text { (2) Card task: all improved (one child did not } \\
\text { complete) }\end{array}$ \\
\hline Reid [45] & $\begin{array}{l}\text { Sample size } \\
\text { Gender } \\
\text { Age range } \\
\text { Diagnosis }\end{array}$ & $\begin{array}{l}\mathrm{n}=4 \\
\text { Not indicated } \\
8-12 \text { years } \\
\text { Spastic quadriplegia (3), } \\
\text { Spastic diplegia (1) }\end{array}$ & $\begin{array}{l}\text { Design: } \\
\text { Single case study } \\
\text { VR system: IREX system } \\
\text { Intervention: } \\
\text { Games to promote upper extremity range of } \\
\text { motion, mobility and strength } \\
\text { Treatment intensity: } \\
1 \times 90 \text {-min session per week, } 8 \text { weeks }\end{array}$ & $\begin{array}{l}\text { (1) Quality of Upper Extremity Skills Test (QUEST): } \\
2 \text { of } 4 \text { children showed clinically significant } \\
\text { improvements } \\
\text { (2) Bruininks-Oseretsky Test of Motor Proficiency } \\
\text { (BOTMP): subtest \#5, item \#6: All children } \\
\text { showed improvements } \\
\text { (3) Orbosity program: percent accuracy: } 2 \text { of } 4 \\
\text { children showed notable improvements }\end{array}$ \\
\hline $\begin{array}{l}\text { You } \\
\text { et al. [46] }\end{array}$ & $\begin{array}{l}\text { Sample size } \\
\text { Gender } \\
\text { Age } \\
\text { Diagnosis }\end{array}$ & $\begin{array}{l}\mathrm{n}=1 \\
\text { Male } \\
8 \text { years } \\
\text { Cerebral palsy with hemiplegia }\end{array}$ & $\begin{array}{l}\text { Design: } \\
\text { Single case study } \\
\text { VR system: } \\
\text { IREX system } \\
\text { Intervention: } \\
\text { Games to promote upper extremity range of } \\
\text { motion, mobility and strength } \\
\text { Treatment intensity: } \\
5 \times 60 \text {-min per week, } 4 \text { weeks }\end{array}$ & $\begin{array}{l}\text { (1) Bruininks-Oseretsky Test of Motor Proficiency } \\
\text { subtest \#5, item \#6 (BOTMP): considerable } \\
\text { improvements } \\
\text { (2) Modified Pediatric Motor Activity Log (PMAL): } \\
\text { considerable improvements } \\
\text { (3) Fugl-Meyer Assessment (FMA): considerable } \\
\text { improvements } \\
\text { (4) fMRI: no observable or meaningful changes in } \\
\text { regions of interest }\end{array}$ \\
\hline \multicolumn{5}{|c|}{ Lower extremity studies } \\
\hline $\begin{array}{l}\text { Brutsch } \\
\text { et al. [47] }\end{array}$ & $\begin{array}{l}\text { Sample size } \\
\text { Gender }\end{array}$ & $\begin{array}{l}\text { With gait disorder: } \mathrm{n}=10 \\
\text { Controls: } \mathrm{n}=8 \\
\text { With gait disorder: } 4 \text { males, } \\
6 \text { females } \\
\text { Controls: } 2 \text { males, } 6 \text { females } \\
\text { With gait disorder: } 14.2 \text { years } \\
\text { Controls: } 11.8 \text { years } \\
\text { Cerebral palsy with diplegia } \\
\text { (3), with tetraplegia (2), Hip } \\
\text { dysplasy (1), cerebral hemor- } \\
\text { rhage (1), MS (1), encephalop- } \\
\text { athy (1), symptomatic SCI (1) }\end{array}$ & $\begin{array}{l}\text { Design: } \\
\text { Within groups (2 groups) } \\
\text { VR system: } \\
\text { Lokomat system } \\
\text { Intervention: } \\
\text { RAGT with instructor encouragement and/or VR } \\
\text { Treatment intensity: } \\
1 \text { session, } 4 \text { conditions } \times 2 \text { min }\end{array}$ & $\begin{array}{l}\text { (1) Motor Output: increased motor output with } \\
\text { instructor encouragement and VR, both } \\
\text { separately and in combination, for all children in } \\
\text { both groups }\end{array}$ \\
\hline $\begin{array}{l}\text { Bryanton } \\
\text { et al. [48] }\end{array}$ & $\begin{array}{l}\text { Sample size } \\
\text { Gender } \\
\text { Age range } \\
\text { Diagnosis }\end{array}$ & $\begin{array}{l}\text { With CP: } \mathrm{n}=10 \\
\text { Without CP: } \mathrm{n}=6 \\
\text { With CP: } 4 \text { males, } 6 \text { females } \\
\text { Without CP: } 2 \text { males, } 4 \text { females } \\
7-17 \text { years } \\
\text { Cerebral palsy with spastic } \\
\text { hemiplegia (8), spastic diple- } \\
\text { gia (2) }\end{array}$ & $\begin{array}{l}\text { Design: } \\
\text { Within subjects (AB-BA design) } \\
\text { VR system: } \\
\text { IREX system } \\
\text { Intervention: } \\
\text { Conventional and VR exercises to improve ankle } \\
\text { dorsiflexion } \\
\text { Treatment intensity: } \\
1 \times 90 \text {-min session }\end{array}$ & $\begin{array}{l}\text { (1) Number of exercise repetitions: all children } \\
\text { completed significantly more repetitions during } \\
\text { Conventional exercises than during VR exercises } \\
\text { (2) Time to complete one exercise repetition: all } \\
\text { children took significantly more time to complete } \\
\text { VR exercises than Conventional exercises } \\
\text { (3) Average hold times: all children showed longer } \\
\text { hold times in the VR exercises than in the } \\
\text { Conventional exercises } \\
\text { (4) Mean ankle range of motion into dorsiflexion: all } \\
\text { children achieved significantly greater range of } \\
\text { motion during the VR exercises than during } \\
\text { Conventional exercises }\end{array}$ \\
\hline $\begin{array}{l}\text { Deutsch } \\
\text { et al. [49] }\end{array}$ & $\begin{array}{l}\text { Sample size } \\
\text { Gender } \\
\text { Age } \\
\text { Diagnosis }\end{array}$ & $\begin{array}{l}\mathrm{n}=1 \\
\text { Male } \\
13 \text { years } \\
\text { Cerebral palsy with spastic } \\
\text { diplegia }\end{array}$ & $\begin{array}{l}\text { Design: } \\
\text { Single case study } \\
\text { VR system: } \\
\text { Nintendo Wii system } \\
\text { Intervention: } \\
\text { Wii games to improve visual perception, posture } \\
\text { and functional mobility } \\
\text { Treatment intensity: } \\
11 \times 60-90 \text { min, over } 4 \text { weeks }\end{array}$ & $\begin{array}{l}\text { (1) Test of Visual Perceptual Skills, ed } 3 \text { (TPVS-3): } \\
\text { improvements in all domains except visual } \\
\text { memory } \\
\text { (2) Postural Scale Analyzer: greater loading on lower } \\
\text { extremities and less reliance on walker, center-of- } \\
\text { pressure sway decreased, increased symmetry of } \\
\text { weight distribution } \\
\text { (3) Functional mobility (ambulation with forearm } \\
\text { crutches): great improvements in distance of } \\
\text { independent ambulation }\end{array}$ \\
\hline
\end{tabular}


Table 1 (continued)

\begin{tabular}{|c|c|c|c|c|}
\hline Source & \multicolumn{2}{|c|}{ Participant characteristics } & Description of treatment & Description of results \\
\hline $\begin{array}{l}\text { Kott } \\
\text { et al. [50] }\end{array}$ & $\begin{array}{l}\text { Sample size } \\
\text { Gender } \\
\text { Mean age } \\
\text { Diagnosis }\end{array}$ & $\begin{array}{l}\mathrm{n}=5 \\
\text { All male } \\
7 ; 5 \text { years } \\
\text { Cerebral palsy with spastic } \\
\text { diplegia (3), spastic hemiplegia } \\
(1) \text {, spastic triplegia (1) }\end{array}$ & $\begin{array}{l}\text { Design: } \\
\text { Within group } \\
\text { VR system: } \\
\text { Desktop system with treadmill } \\
\text { Intervention: } \\
\text { Treadmill therapy to increase functional mobility } \\
\text { Treatment intensity: } \\
9 \mathrm{~h} \text {, in } 10-12 \text { sessions, over } 3-4 \text { weeks }\end{array}$ & $\begin{array}{l}\text { (1) SWOC: significantly increased speed for Walk- } \\
\text { Glass condition } \\
\text { (2) GMFM- } 88 \text { dimension E: significant increase in } \\
\text { percentage of items accomplished } \\
\text { (3) Treadmill speed: significant increase in speed } \\
\text { from initial to final session }\end{array}$ \\
\hline Reid [51] & $\begin{array}{l}\text { Sample size } \\
\text { Gender } \\
\text { Age range } \\
\text { Diagnosis }\end{array}$ & $\begin{array}{l}\text { VR group: } \mathrm{n}=3 \text { Control: } \mathrm{n}=3 \\
\text { Not indicated } \\
9-12 \text { years } \\
\text { Cerebral palsy with spastic } \\
\text { quadriplegia (4), spastic diple- } \\
\text { gia (2) }\end{array}$ & $\begin{array}{l}\text { Design: } \\
\text { Between groups } \\
\text { VR system: } \\
\text { IREX system } \\
\text { Intervention: } \\
\text { Exercises focused on upper extremity and trunk } \\
\text { control } \\
\text { Treatment intensity: } \\
2 \times 90 \text {-min, } 4 \text { weeks }\end{array}$ & $\begin{array}{l}\text { (1) SACND: improvements in VR group in posture } \\
\text { measures during rest and reaching }\end{array}$ \\
\hline
\end{tabular}

The authors created a VR game to reinforce the achievement of the target EEG signal. If a participant achieved the target amplitude, a dinosaur's egg would hatch in the $\mathrm{VE}$ and a part of a dinosaur puzzle would be filled in. Completion of the puzzle signaled the end of the game. After eight 20-min sessions, both the biofeedback-withVR and biofeedback-only groups improved on the Continuous Performance Task (CPT) on the attention and impulsivity dimensions. The biofeedback-with-VR group also showed a significant decrease in reaction time on the $\mathrm{CPT}$, indicating that they were attending to the task and responding more efficiently. Although both treatment groups showed improvements in performance as compared to the control group, these results indicate that biofeedback with VR may be more effective than biofeedback alone.

Othmer and Kaiser [33] investigated VR with neurofeedback in an intervention with 46 children with ADHD, epilepsy and mood disorders. The intervention consisted of a minimum of twenty 30 -min sessions using the Neurocybernetics 2-channel EEG biofeedback system. The children were given the choice to play either $2 \mathrm{D}$ simple games or 3D virtual games. Similar to the setup in Cho et al. [32], the games were designed to reinforce a certain range of target amplitudes. After the intervention, the participants who played the 3D virtual games scored significantly higher on the Symbol Digit Modality test (SDM) [52], which is a test of general cognitive ability. The same 3D group also showed the greatest improvements on the impulsive dimension of the Test of Variables of Attention (TOVA) [53]. Thus, the authors concluded that combining 3D visual games with neurofeedback techniques improved the targeted outcomes. The authors also noted that the subjects who engaged with the $3 \mathrm{D}$ games completed a marginally significantly greater number of sessions than those in $2 \mathrm{D}$ training. Thus, the greater improvements in the $3 \mathrm{D}$ group may be due to increased treatment time, rather than the type of treatment itself.

Using a more homogeneous sample, Yan et al. [34] evaluated 12 participants in a neurofeedback intervention with VR. The participants were clinically diagnosed with ADHD, and were between the ages of 8 and 12. The VR game consisted of 3 spaceships, the 'commander' of which was controlled by the child's EEG signal: if the child's signal fell within the targeted range, the ship would speed up; if the signal deviated, it would slow down. After twenty 30-min training sessions, the children showed significant improvements on the impulsivity and inattentiveness subscales of the Integrated Visual and Auditory-Continuous Performance Test (IVA-CPT) [54], although there were no improvements in the hyperactivity subscale. The authors concluded that their system was effective in improving the attention and impulsivity of children with ADHD.

For children with cerebral palsy, VR has been integrated with treadmill training, which is an effective intervention for lower-extremity rehabilitation [55]. Kott et al. [50] displayed a virtual fantasy world in front of a treadmill to encourage children with cerebral palsy to complete their walking therapy. The researchers developed two virtual story scenarios where the child played a character within the story. The child was employed with 
the task of 'saving a princess' or 'defeating a dragon'. The progression and outcome of the virtual story were calibrated to the child's walking performance. A successful and happy ending to the story was only achieved if the child reached and maintained his or her walking goals as the virtual story unfolded. Five boys with cerebral palsy ages 5-9 participated in the training program. The outcome assessments included the Standardized Walking Obstacle Course (SWOC) [56] and items on the Gross Motor Function Measure-88 (GMFM-88) [57]. Each child underwent $9 \mathrm{~h}$ of VR treadmill training in $10-12$ sessions over 3-4 weeks. The speed and duration of each session were calibrated to the target heart rate for each child. After training, the children showed a decrease in mean performance times on the SWOC, which indicated increased walking speed. There was also a significant increase in the percentage of items completed on the SWOC. The authors noted that the short-term intensive training program achieved results that are typically only achieved over 3-4 months [58]; however, the maintenance and continued improvements of the children were not assessed.

A more recent study has applied a combination of robotics and VR to lower-limb rehabilitation. Brutsch et al. [47] integrated the Lokomat System (Hocoma Inc., Rockland, Mass., USA) with VR to target lower-limb functioning through Robotic Assisted Gait Training (RAGT). The efficacy of the Lokomat in improving gait has already been documented; however, the repetitive nature of the exercises often hinders motivation or adherence to the program. In the current study, the Lokomat System was used as a multidimensional feedback system during a virtual game of soccer. The feedback capabilities of the device allowed the children to 'feel' the weight and forces exerted on and by the soccer ball. The VR-integrated Lokomat program was evaluated with 10 children with neurological gait disorders, 5 of whom were diagnosed with cerebral palsy (mean age 14.2 years). A healthy control group of 8 children was included (mean age 11.8 years). The degree of active engagement in the Lokomat exercises was evaluated for both groups of children during 4 conditions: (1) without instructor encouragement or VR, (2) with instructor encouragement only, (3) with VR, and (4) with both instructor encouragement and VR. The results of the study showed that active engagement in the Lokomat exercises significantly increased when either or both instructor support or VR engagement was included. There were no differences in the degree to which active engagement increased between instructor encouragement and the presence of VR. Thus, this study offers sup- port for the use of VR as a tool for active engagement, which is considered the major role of VR in feedback-focused systems.

VR has shown potential as an additional reinforcement for treatments whose efficacy is already established, such as neurofeedback [59] and mobility training [55]. The studies reviewed in this section have used VR as an added tool to retain the children's motivation and engagement in the treatment. All studies combining VR with neurofeedback used a variation of the CPT as an outcome measure. The CPT is the most frequently used laboratory assessment for ADHD, and has demonstrated good discriminative and predictive validity [60]. The SWOC [56] and GMFM-88 [57] also provide standardized and functional assessments of meaningful change. The results thus indicate that meaningful changes were obtained in all studies; however, the specific impact of VR on these meaningful changes is still unknown.

Of the 5 studies exploring feedback-focused VR systems, only 1 study, Cho et al. [32], compared the efficacy of a VR program with a traditional non-VR program. While Othmer and Kaiser [33] and Brutsch et al. [47] both used between-groups designs, the former did not randomize subjects, and the latter investigated the outcomes of the same intervention with both clinical and nonclinical groups. Thus, a major limitation of these studies is the lack of between-groups studies with sufficiently large sample sizes. Researchers need to verify the added contribution of VR to existing, empirically validated treatments. Positive evidence from large-scale comparison studies would support further research for the use of VR as a reinforcement tool. In addition, although results from Brutsch et al. suggest that VR plays a role in increasing active engagement, current studies have not yet characterized the type or degree of the therapeutic impact of VR. Thus, although these studies suggest that VR increases the efficacy of existing programs by increasing motivation and engagement, the quality and quantity of this have not yet been measured.

\section{VR Systems with Gesture-Based Interaction}

Gesture-based interaction systems have incorporated specialized cameras that can capture a child's movements, or gestures, which are then projected in real time into the VE to facilitate interactions between the child and virtual objects. There are two basic systems available with these capabilities: those designed specifically for rehabilitative purposes and those designed primarily for 
entertainment purposes. All of these motion capture systems allow the children to see themselves within the VE while performing the activities. While both types have similar capabilities and provide similar types of games/ applications, the entertainment systems are far more affordable and accessible for the general population. Specialty rehabilitation systems, however, have valuable built-in capabilities for data collection which allow individual performance to be monitored and modified accordingly. While gesture-based systems have been used exclusively to address primary deficits in children with cerebral palsy, there is increasing interest in extending the use of this technology to conditions such as autism [61]. Gesture-based systems offer the unique experience of 'seeing oneself' within the virtual world, which may lead to increased engagement within the environment and a sense of control over the cause-and-effect of events occurring within the VE.

Reid [45] used the Interactive Rehabilitation and Exercise System (IREX; GestureTek Health, Toronto, Ont., Canada) program to address the upper-extremity deficits in 4 case studies of children with cerebral palsy, ages 8-12 years. The VR intervention consisted of one 1.5hour session per week for 8 weeks. Each child spent approximately 15 min playing each of 5 IREX applications: Orbosity (Birds and Balls), Drums, Paint, Volleyball and Soccer. Upper-extremity function and quality of movement were assessed before and after the intervention with 3 tests: the Quality of Upper Extremity Skills Test (QUEST) [62]; Item \#6 of Subtest \#5 from the BruininksOsertesky Test of Motor Proficiency (BOTMP) [63] and a measure of performance accuracy from the Orbosity (birds and balls) application. After the 8-week intervention, the children showed minimal changes on the QUEST; however, their BOTMP scores increased and their percent accuracy on the Orbosity application either stayed the same or improved slightly. While this study includes only 4 case studies, it offers promising preliminary data on the effectiveness of IREX in upper-extremity rehabilitation.

Using the same IREX programs and treatment intensity discussed above, Reid [51] performed a betweengroups study with 6 children with cerebral palsy to evaluate the influence of upper-extremity exercises on sitting posture. Reid utilized the Sitting Assessment for Children with Neuromotor Dysfunction (SACND) [64], which measures postural tone, postural alignment, proximal stability and balance, and found measurable improvements in the experimental group's seated postural control. No changes were found in the control group on any aspect of sitting posture as measured by the SACND. Although the IREX exercises chosen for this study emphasize upper-extremity movement, the engagement and participation of the trunk muscles in maintaining posture during these activities resulted in improvements in seated postural control as well.

You et al. [46] sought to verify the impact of IREX on upper-extremity function with a single-case study of an 8 -year-old child with hemiparetic cerebral palsy. The significance of the VR intervention was also evaluated cortically using functional magnetic resonance imaging (fMRI), which is able to show which areas of the brain are active during a specific cognitive or motor task. The child participated in a VR intervention which involved five 60min sessions each week for 4 weeks. The participant played the following IREX games: Birds and Balls, Conveyor and Soccer. Pre- and postintervention assessments included the following: Item \#6 of Subtest \#5 from the BOTMP [63]; the modified Pediatric Motor Activity Log questionnaire (PMAL) [65]; and the upper-limb subtest of Fugl-Meyer assessment (FMA) [66]. In addition, the fMRI focused on specific regions of the brain during elbow flexion and extension movements: primary sensorimotor cortex, premotor cortex and supplementary motor area. These regions have been shown to have potential for change following motor rehabilitation [67]. Following the 4 -week intervention, the participant showed significant improvements in all 3 motor assessments; however, the fMRI results indicated that the VR intervention had not significant impact on the degree or location of brain activation. Therefore, the findings support IREX in improving the quality and quantity of functional motor skills in this child with cerebral palsy; however, the authors encountered difficulties in detecting changes on a cortical level.

The efficacy of IREX for lower-extremity rehabilitation was compared with conventional lower-extremity exercises by Bryanton et al. [48]. The participants included 10 children with cerebral palsy and 6 able-bodied children, between 7 and 17 years. The authors used a singlesubject AB-BA design with type of exercise (VR or conventional) counterbalanced between participants. The focus of both types of exercise was to improve the voluntary dorsiflexion movements of the ankle. In one 90 -min session, each child completed ankle dorsiflexion exercises in 10-min blocks. Each block involved 2 min of each exercise ( 2 exercises for VR, 2 for conventional), with a 1-min break at the half-way point. For both VR and conventional activities, the children were instructed to dorsiflex the ankle to the end of range and hold the maxi- 
mum position for $3 \mathrm{~s}$ and then relax and repeat. The IREX activities were 'Coconut Shooters' and 'Ninja Flip'. Conventional activities of ankle dorsiflexion were performed on a chair and on the floor. An electrogonimeter was used to measure ankle joint range of motion during all of the activities. The authors reported that all children showed a greater range of motion, greater hold time and greater interest during the VR exercises, despite fewer exercise repetitions compared with the conventional exercises. This suggested that perhaps the number of movement repetitions is not the primary factor in ankle joint rehabilitation; perhaps quality of movement, including reaching maximum range of motion and longer hold time, is of greater importance. Thus, interaction and immersion within the environment may be a factor promoting greater quality of movement during lower-extremity exercises.

Similar to the IREX program used in the previous studies, Odle et al. [44] created the customized Hands-Up (New Jersey Institute of Technology, Newark, N.J., USA) system which uses specialized tracking technology to capture the movements of specific parts of the body based on attached markers. The markers can be placed on any part of the child's body in order to collect specific data regarding the speed, accuracy, level of difficulty and duration of specific movements. Three boys with cerebral palsy, ages 4,10 and 12 , participated in a 5 -week intervention focused on the remediation of hand function. The intervention consisted of one 60-min session per week for 5 weeks. The children were assessed using functional tasks with Velcro strips and a deck of cards. The authors reported that all the children improved on the functional tasks that they were assessed on (1 participant did not complete the cards task). These results are promising and will shape a larger study that will hopefully integrate more standardized outcomes such as the QUEST [65] and Item \#6 of Subtest \#5 from BOTMP [63], which were used in both Reid [45] and You et al. [46] above.

Although IREX and Hands-Up have been designed specifically for rehabilitation purposes, the commercially available Sony Playstation 2 EyeToy (Sony Computer Entertainment America, Foster City, Calif., USA) has similar capabilities. Jannick et al. [43] explored the use of the Sony EyeToy with selected EyeToy mini-games to improve upper-extremity movement in 10 children with cerebral palsy, ages $7-16$. The children were randomly assigned to either the control or experimental group. The control group received regular physiotherapy while the experimental group received VR integrated into their regular physiotherapy. The total treatment intensity for both groups was 30-min sessions, twice per week for 6 weeks. The children in the experimental group played games from a selection of: Kung Foo (hit virtual characters on-screen), WishiWashi (wash virtual windows) and KeepUps (keep up ball with arms). The Melbourne Assessment of Unilateral Upper Limb Function (MAUULF) [68] was used to assess the quality and quantity of upperlimb function in the children. Following the 6-week intervention, 7 of the 10 children made no or negligible improvements. Only 2 children in the experimental group made improvements. The authors stated that there are problems with using commercially available technology in rehabilitation because such systems were not designed with a rehabilitative approach. While the EyeToy is a promising tool, modifications are necessary to make it appropriate for rehabilitation purposes.

Li et al. [42] have further explored the use of the EyeToy for upper-extremity rehabilitation in children with cerebral palsy. The authors have developed an in-home rehabilitation system that was evaluated in 5 children with cerebral palsy (mean age 8.1 years). Li et al. have approached the use of entertainment technology within rehabilitation by first determining the specific EyeToy games that elicit the specific, target motor behaviors. The children played two EyeToy games: Secret Agent and Mr. Chef. Note that these games differ from those chosen by Jannick et al. [43] above. The results of the study of Li et al. [42] indicate that their in-home VR program effectively elicited the upper-extremity movements that were targeted for therapy. In addition, these movements were elicited with a sufficient degree of repetition. Taken in combination with the results of the study of Jannick et al. [43] above, the current study indicates that not all entertainment games have the capacity to elicit specific motor behaviors. The first step in introducing entertainment systems into rehabilitation is to determine which games have therapeutic potential.

Another entertainment system, Nintendo Wii (Nintendo Domestic Distributor, College Point, N.Y., USA) integrates a more advanced approach to motion capture capabilities for gaming purposes. An integrated tracking device is used to track the movements of a hand-held remote control. This has significantly increased the motion sensitivity to gross upper-extremity movements, and thus has allowed the development of more interactive and complex games, such as tennis, golf and bowling. Deutsch et al. [49] evaluated the Wii system as a rehabilitation tool to improve posture and lower-extremity difficulties in an adolescent with cerebral palsy. The participant was 13 years old with spastic diplegia and co-occurring cognitive and attention deficits. He participated in 11 sessions 
over 4 weeks, each session lasting from 60 to $90 \mathrm{~min}$, in which he played various Wii games, including golf, bowling, boxing, baseball and tennis. The authors reported improvements in postural control at the end of the 4 -week intervention: there was greater loading on the lower extremities and less reliance on the walker, the center of pressure sway decreased, and his weight distribution on the medial-lateral and anterior-posterior axes was more symmetrical. In addition, the participant improved in functional mobility, which was measured based on the distance he was able to achieve with forearm crutches. The traveled distance increased from $15 \mathrm{ft}$ before training to $150 \mathrm{ft}$ after training, and continued to improve beyond the VR intervention. This offers support for the continued exploration of using entertainment systems for children with cerebral palsy, as positive results were found in both standardized measures of postural control, as well as in meaningful clinical changes in functional mobility.

Overall, the studies above provide preliminary support for both customized and entertainment gesturebased systems. Three studies $[43,48,51]$ compared VR therapy to conventional or no therapy. Although Reid [51] and Jannick et al. [43] performed randomized controlled studies, their group sizes were very small, and thus, only preliminary conclusions can be drawn from them. Similar to the discussion of the studies in the last section, robust comparisons, with sufficiently large sample sizes, are necessary to determine the effect of VR independently of, and in conjunction with, conventional therapies.

In terms of outcome measures, the studies in this section on upper-extremity rehabilitation were relatively consistent in using standardized measures of upper-limb function such as the QUEST [62], BOTMP [63] and MAUULF [68]. However, measures of generalization and functional assessment should also be included to assess the ecological validity of the VR intervention.

An additional limitation of specialized rehabilitation systems is their cost (e.g. USD 13,000 for IREX; www. flaghouse.ca). This limits the affordability and therapeutic usefulness of these systems for research laboratories and large rehabilitation centers. Alternatively, increased knowledge regarding the rehabilitative relevance and usefulness of entertainment systems such as Sony Playstation and Nintendo Wii may generate support for these systems as acceptable rehabilitation alternatives. It would be interesting to evaluate the efficacy of the new Nintendo Wii Fit (Nintendo Domestic Distributor, VR systems with haptic-based interaction) for rehabilitation populations, as this new commercial system integrates gesturebased technology to provide physical fitness regimes such as yoga and pilates. The Wii Fit is able to monitor individual progress on activities and provide detailed feedback while maintaining affordability to the general public. All of the discussed gesture-based systems have focused predominantly on physical rehabilitation; however, this technology can be extended to cognitive populations such as children with autism, brain injury, and ADHD in order to increase motivation and interactivity. For example, in our VR lab at the University of Toronto, we are currently testing the use of gesture-based technology to facilitate interaction in a cognitive rehabilitation program for children with autism. Gesture-based interaction systems have the potential to explore beyond the realm of physical disabilities.

\section{VR Systems with Haptic-Based Interaction}

The final class of VR display systems incorporates haptics: the sense of touch. The simplest, traditional haptic interfaces include computer mice, joysticks and touch screens. These devices offer a touch-based interaction between the user and computer; however, they do not offer direct or realistic haptic feedback. More refined haptic technologies, such as sensor gloves and robotics, do offer direct haptic feedback. While each type of haptic device will be discussed in the context of rehabilitation, note that the goals of the treatment programs are not necessarily focused on the remediation of deficits associated with hand motion or sensation. The sense of touch is often used as an additional medium through which children can interact within the VE.

The simplest way to integrate the sense of touch into a human-computer interaction is through the computer mouse. The mouse is easy to integrate into programs because of its availability, affordability, compatibility with existing computer programs and user familiarity. Cho et al. [31] created a virtual classroom on a desktop computer, which required navigation via a mouse. Twenty-eight adolescents between 14 and 18 years participated in the study. All of the subjects had committed crimes and demonstrated difficulty in learning in school. Although they did not have the formal diagnosis of ADHD, they were reported to be inattentive, impulsive, hyperactive and distractible. The participants were divided into 3 groups: VR, non-VR and control. The VR group underwent 8 VRbased cognitive training sessions over 2 weeks. The nonVR group underwent the same cognitive training program in a non-VR setting. The authors developed 2 cognitive training courses: the Virtual Reality Comparison 
Training Task and the Virtual Reality Sustained Attention Task. The former requires the participant to determine if the displayed items are the same or not, while the latter requires the participant to press the mouse when a certain target is displayed in sequence. Both training programs involved graded levels of difficulty. After the training program, both the VR and non-VR groups obtained significantly higher scores on the CPT; however, the improvement was greater for the VR group. Recall that the $\mathrm{CPT}$ is used as a laboratory tool to assess the severity of symptoms, and that it can indicate meaningful changes in the severity of the impairments. Although positive results were obtained with the limited mouse-only haptic interaction, there is room to explore whether more complex haptic devices can increase engagement in the repetitive tasks presented in the virtual classroom.

Mitchell et al. [37] developed and tested a virtual café for children with autism to address impairments in social interaction. The participants were required to complete specific tasks in the virtual café, such as ordering and paying for a drink, and finding a place to sit. Again, navigation was achieved through a mouse. A VR social-understanding training program was administered to 6 adolescents, 14-16 years old, each with formal diagnoses of an autism spectrum disorder. During the training sessions, 4 types of activities were taught and practiced. These activities were graded in difficulty and created based on certain social conventions associated with finding a seat in an empty or crowded café, ordering, paying and engaging in appropriate conversation with others. The social understanding of these adolescents was assessed using ratings of their verbal descriptions of their decision-making process of how they would behave in two different social scenarios: a café and a bus. The former was similar to situations encountered in the virtual café, while the latter assessed the generalizability of the participants' learned social understanding. The results were variable and only 2 participants showed gains in social knowledge in both scenarios. Actual performance in real situations was not assessed. As real-café interactions usually require touching objects, such as money or coffee mugs, the integration of more complex haptics into this type of program may facilitate more realistic interaction between the user and VE. Increased realism would influence the degree of ecological validity achieved and subsequent degree of skill transfer.

Increasing in complexity, touchscreen technology has facilitated human-computer interaction without the traditional mouse and joystick. Herrera et al. [36] created a virtual supermarket on a flatscreen monitor to teach 2 children, 8 and 15 years old, how to think abstractly and play imaginatively. The children explored the virtual supermarket through touching the screen. They interacted with objects in increasing more imaginative ways, such as transforming a pair of flying pants into a highway. The authors assessed the outcomes using a test of functional object use (i.e. how an object should be used), the Symbolic Play Test (SPT) [69], the Test of Pretend Play (ToPP) [70] and the Imagination and Magic Understanding Tests. Both children improved on all tests except on the SPT. The authors concluded that their VR tool is useful in improving the symbolic thinking skills of these children, and that these skills translate into concrete symbolic play behaviors. The touchscreen facilitated easy interaction between the children and the display interface, and allowed the instructor to participate as well. This multidimensional interaction is naturally afforded by touchscreen technology; it allows interaction between child and computer, instructor and computer, and instructor and child.

DiamondTouch (Circle Twelve Inc., Framingham, Mass., USA), a state-of-the-art multiuser and multitouch display table, allows many people to interact with objects on the table-top display screen simultaneously through touch. Similar to the touchscreen in Herrera et al. [36], the DiamondTouch table immerses users in an imaginative scene where their actions and decisions have realtime consequences within the virtual world. DiamondTouch technology was integrated with the StoryTable interface to allow multiple children to create an imaginative story together by selecting, combining and sequencing a series of on-screen virtual characters and events. Some story elements required 2 children to touch it before being integrated into the story, reinforcing joint attention, communication and negotiation. Bauminger et al. [35] evaluated this system with 3 dyads of children with autism, ages 9-11 years, to teach and reinforce key social skills such as eye contact, turn-taking, sharing and jointdirected behavior. During the intervention, the dyads were instructed to create and narrate stories using backgrounds and characters that were jointly chosen. The instruction was focused on three goals: performing shared activities, helping and encouraging each other, and persuading and negotiating when creating the stories. Ratings of social behaviors from videos of the StoryTable sessions were completed; in addition, the authors assessed the generalizability of the children's social skills through a Lego-like assembly game, MarbleWorks. After the training sessions, the children were all rated as having more occurrences of positive social behaviors during 
StoryTable and more positive behaviors during MarbleWorks. In addition to the improvements in positive social behaviors, the quality of play of the dyads improved from simple parallel play without eye contact to complex, coordinated play. Lastly, the types of meaningful utterances transitioned from less narrative utterances (about technical aspects of the program) to more narrative, relevant utterances (about characters, setting, and plot of the story). The authors concluded that the StoryTable intervention increased both the quantity and the quality of social interaction between the dyads. These improvements were generalized to a similar task, MarbleWorks. Both Herrera et al. [36] and Bauminger et al. [35] provide evidence that touchscreen technology shows great promise in promoting creative and imaginary play between multiple users. Future studies should consider using typical peers as participants with this multiuser technology, rather than atypical peers. Research has shown that same-aged, typical peers serve as effective role models for children with autism to reinforce prosocial and age-appropriate behaviors [71]. It is important to note that although devices such as the mouse, joystick and touch-screen cannot simulate real-life haptic interactions, such as feeling the texture of a surface, incorporating the sense of touch adds yet another layer of interaction within the program. Participating in real-time cause-and-effect behaviors may contribute to the overall sense of presence and motivation of the child during the intervention program.

The next 3 studies demonstrate the extent to which researchers have achieved complex, dynamic and realistic haptic-based interaction within a virtual environment. Chen et al. [38] attempted to compensate for the weaknesses of the Sony Playstation EyeToy system by designing a complementary VR system designed specifically for hand rehabilitation. Their VR-based hand rehabilitation training system uses a specialty sensor glove, the 5 Digital Data Glove (iReality.com Inc., San Mateo, Calif., USA). The games show a $3 \mathrm{D}$ virtual hand which corresponds to the movements created with the glove. The degree of difficulty of the games could be adjusted based on the diameter of the objects and the degree of flexion required by the fingers. This VR-based hand rehabilitation training system was used as a separate but complementary tool to the EyeToy mini-games. Four children ages 4-8 with cerebral palsy participated in the comprehensive intervention. Each week, each child would spend approximately $45 \mathrm{~min}$ with the VR hand tool and $75 \mathrm{~min}$ with the EyeToy. The assessments included measurements of reaching kinematics, based on a 'mail delivery' task designed by the authors, as well as fine motor skill assessments based on the Peabody Developmental Motor Scales, 2nd edition (PDMS-II) [72]. Postintervention analysis indicated that performances on the 'mail delivery' task were inconsistent; only 1 participant obtained and maintained improvements on the items. For the fine motor assessments, all participants improved after the intervention; however, only 1 participant's improvements were significant and maintained. This intervention, therefore, offers only emerging evidence that integrating sensor gloves into VR programs may exert a positive influence on hand mobility and function.

Huber et al. [40] went further than merely using two separate training programs within one intervention. They harnessed the power of the Playstation system and developed compatibility between this system and a customized sensor glove. The 5DT 5 Ultra sensor glove (5DT Inc., Irvine, Calif., USA) is able to measure the flexion and extension of each finger with fiber-optic sensing devices. Customized hand rehabilitation programs were designed to be compatible with the Playstation system and to target finger range-of-motion and finger velocity. These games allowed the child to see a simulated hand in the VE which could be controlled by the child's own finger movements in the glove. The VR system was set up in each child's home for remote telerehabilitation. Three children with hemiplegic cerebral palsy, between 13 and 15 years, participated in the initial studies with this telerehabilitation system. All children were selected for good cognitive function and ability to provide feedback. The participants were asked to practice on the VR system for 30 min per day. In their initial reports, Huber et al. [40] report that all 3 children showed improvements in some areas of their hand function, based on their ability to perform activities of daily living, including carrying a grocery bag, holding a spoon, playing sports and dressing themselves. In a follow-up publication [41], the same group of researchers reported that the occupational therapy assessments of these 3 children showed improvements at 3 months on the Jebson test of unilateral hand function [73]; however, there were no noted improvements on the BOTMP [63]. This is not surprising since the sensing gloves were fitted only on the child's plegic hand, and therefore the exercises were focused on unilateral movements. Interestingly, the intervention administered in this study was done in the child's home through the telerehabilitation method. Future studies may focus on integrating VR systems into home rehabilitation programs and on what impact this might have on treatment length, intensity and overall program adherence. 
Advancing beyond the capacities of sensor gloves, Fluet et al. [39] introduced the use of the HapticMaster (New Jersey Institute of Technology), which integrates force-controlled haptic robotics. The robot acts as the interface between the child and the VE. With this system, the child grasps onto a ring gimbal in order to exert forces on the attached robotic system, which translates these motions into 3D, real-time movements on screen. In turn, the robot is able to transmit haptic feedback to the child so that the child is able to 'feel' the hard or elastic surface of a virtual object as well as the 'flow' of a fluid's velocity. Fluet et al. [39] integrated the HapticMaster into 5 gaming simulations focused on improving the movements of the upper extremities. Two groups of children with cerebral palsy ( 4 in each group) between 5 and 16 years participated in 2 phases of the intervention. The first group completed 1-hour sessions, 3 days per week for 3 weeks. The second group was provided the same treatment intensity, but completed the sessions in a summer camp setting where they were also receiving other treatments. The outcome assessments included kinematic and kinetic measurements (hand movement speed, smoothness of endpoint trajectory), as well as movement duration during the Bubble Explosion game. At the end of the 3-week intervention, both groups showed improvements; however, the second group improved more. The authors contributed this greater improvement to the amount of nonVR therapy that the second group was receiving. Deconstructing the independent and combined impacts of standard therapy and VR will be important in formulating treatment programs for clinical practice.

Similarly, the limitations discussed with feedback-focused and gesture-based systems also apply to studies exploring haptic-based VR systems. Firstly, the overwhelming majority of studies included in this review have used within-groups designs or case studies with a small number of subjects. To address the difficulty of performing large-scale group studies, the efficacy of a given program may be determined through robustly designed singlesubject studies. Variations on this design, including multiple baselines and nonconcurrence, allow for control over extraneous factors such as maturation, and ease the difficulties of participant recruitment. This single-subject approach is useful to determine the efficacy of a single intervention; however, large-scale comparison studies are still necessary to evaluate the benefits of using VR over conventional therapies. Without these studies, the therapeutic impact of VR cannot be determined.

In addition, the outcome measures chosen for a study need to be consistent across studies. New tests should be described in a way that other researchers can employ them. The 'mail delivery task' designed by Chen et al. [38] is a model example; the task was described in great detail in the article. A more holistic view should also be considered when choosing outcome measures. The studies included in this review focused mainly on the assessment of isolated skills or motor behaviors, rather than functional activities that impact a child's quality of life. Evaluating functional outcomes, such as activities of daily living, will allow the researcher to assess the degree of skill generalization from the VR therapy into real-world activities.

In terms of the technology itself, although the quality and degree of human-computer interaction can be enhanced with specialty haptic devices such as touchscreens, gloves and robotics, the traditional computer mouse remains the most cost-effective and accessible device for both rehabilitation facilities and private homes. Particularly in the case of the latter, having simpler VR systems in the home may serve to increase adherence to treatment programs by increasing engagement in the activities and reducing the need to commute to rehabilitation centers. Although haptic-based interactivity may be limited by the computer mouse, increasing sophistication of realistic computer gaming technology has a significant impact on the degree of visual resolution of the programs, facilitating increased immersion. In addition, it is much more difficult and resource-consuming to find expert programmers and necessary software and hardware resources to design and build customized systems. Thus, relying on available computer technology, devices and experts may prove to be a more cost-effective approach to developing accessible VR rehabilitation technology.

\section{Future Directions}

Three key themes for future research have emerged from the review presented in this paper. All three consider the effectiveness of a VR intervention from a different perspective: the cost-benefit perspective, the therapeutic standpoint and the values and views of society.

First, although state-of-the-art and customized technologies have shown great promise towards increasing the quality of human-computer interactivity, they are limited by the extreme costs and required expertise necessary to use them. Consistent with the recent decrease in using expensive HMD systems in rehabilitation, research interests should continue to focus on the development of affordable options such as computer-based sys- 
tems or modified entertainment systems. Programs made for these systems will have an impact on a significantly greater number of children as compared to high-end systems that would be limited in availability and affordability.

Secondly, the goals of using VR as a rehabilitation tool need to be addressed. The current review focused on the remediation of primary behavioral deficits in children with cerebral palsy, ADHD and autism. However, all three disorders also have well-documented associated cognitive deficits [74-76]. VR has the potential to address both cognitive and behavioral impairments of these disorders. Wang and Reid [61] present a thorough discussion of this approach in autism. Akhutina et al. [77] present a preliminary exploration of addressing spatial functioning impairments in children with cerebral palsy. Thus, there is great opportunity to use interactive technology as a holistic intervention to address broad ranges of impairments.

In addition, further exploration into feedback-focused VR systems may influence the prescribed treatment length, intensity and overall efficacy of existing interventions. In the field of ADHD, for example, cognitive-behavioral modification could be integrated with VR capabilities. Children with autism may benefit particularly well from VR-integrated interventions: firstly, children with autism are acute visual learners and are often easily engaged by computers and television [25], and, secondly, some well-established treatments, such as applied behavioral analysis [22], are founded on principles of reinforcement. Thus, VR has potential to be an engaging reinforcer in treatments for these children.

Lastly, the validity of VR interventions is a field yet to be explored. The ecological validity of a VR program is important to facilitate the generalization of novel skills outside the training environment. Although high ecological validity is believed to increase the probability that skills learned in the simulated environment will transfer or generalize to the real world [27], this has not yet been verified in VR intervention studies. Thus, VR intervention studies should include specific measurements of skill transfer. In addition, high social validity is necessary to promote the acceptance and potential use of a VR program within the community. The value of parent and therapist perspectives cannot be understated; parents and therapists may decide against using specific empirically validated interventions for reasons overlooked in the research context.

As discussed previously, although randomized controlled clinical trials are upheld as the gold standard in establishing efficacy [26], the heterogeneous nature of neurodevelopmental disorders makes it difficult to obtain homogeneous groups for these trials. Even smallerscale trials that do use homogeneous groups may generate results that are difficult to generalize to the broader clinical population. An alternative approach to initially establishing intervention efficacy is to use single-subject methodology which may help to create a characteristic profile of children who may benefit the most from a given intervention [78]. In time, specific VR interventions may then be combined into comprehensive, manualized programs and evaluated through large-scale clinical trials.

\section{Conclusion}

The objective of this review was to provide a synthesis of the research in the past decade that has used VR as an intervention tool in pediatric neurorehabilitation to address key impairments in children with ADHD, autism and cerebral palsy. The review focused on the types of interactivity afforded by different VR systems, the types of children who have benefitted from each system and directions that future research may explore. As suggested by this review, the potential of using VR with children with disabilities will hopefully stimulate interest and discussion for continued use and research with virtual technology within the field of pediatric neurorehabilitation.

\section{Acknowledgements}

This paper was supported by a Masters level award to M.W. (Autism Scholar's Award 09/10, Ontario Council of Graduate Studies). This work was completed as part of M.W.'s Master of Science degree at the University of Toronto.

References

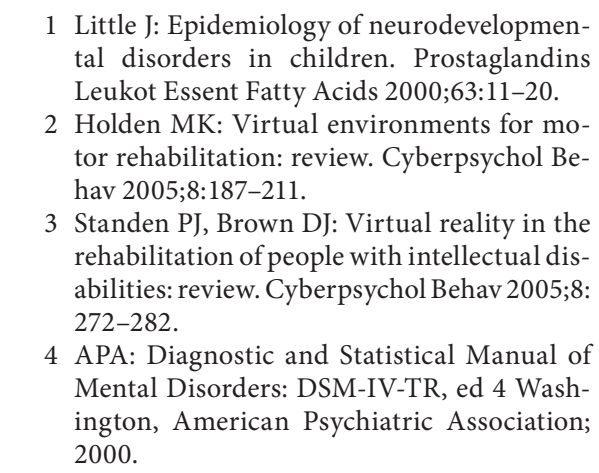

Wang/Reid
16

Neuroepidemiology 2011;36:2-18 
5 Jones MW, Morgan E, Shelton JE: Cerebral palsy: introduction and diagnosis (part I). J Pediatr Health Care 2007;21:146-152.

6 Burdea G, Coiffet P: Virtual Reality Technology. Hoboken, Wiley, 2003.

-7 Self T, Rosalind RS, Weheba G, Crumrine D: A virtual reality approach to teaching safety skills to children with autism spectrum disorder. Top Lang Disord 2007;27:242-253.

8 Witmer BG, Jerome CJ, Singer MJ: The factor structure of the presence questionnaire. Presence 2005; 14:298-312.

$\checkmark 9$ Miller S, Reid D: Doing play: competency, control and expression. Cyberpsychol Behav 2003;6:623-632.

10 Witmer BG, Singer MJ: Measuring presence in virtual environments: a presence questionnaire. Presence 1998;7:225-240.

-11 Slater M, Guger C, Edlinger G, Leeb R, Pfurtscheller G, Antley A, Garau M, Brogni A, Friedman D: Analysis of physiological responses to a social situation in an immersive virtual environment. Presence 2006;15:553569.

12 Sacau A, Laarni J, Hartmann T: Influence of individual factors on presence. Comput Hum Behav 2008;24:2255-2273.

13 Rizzo A, Kim GJ: A SWOT analysis of the field of virtual reality rehabilitation and therapy. Presence 2005;14:119-146.

14 Toplak ME, Connors L, Shuster J, Knezevic B, Parks S: Review of cognitive, cognitivebehavioral, and neural-based interventions for attention-deficit/hyperactivity disorder (ADHD). Clin Psychol Rev 2008;28:801-823.

15 Wolf JM, Fein DA, Akshoomoff N: Autism spectrum disorders and social disabilities; in Hunter SJ, Donders J (eds): Pediatric Neuropsychologial Intervention. New York, Cambridge University Press, 2007.

16 Jones MW, Morgan E, Shelton JE: Primary care of the children with cerebral palsy: a review of systems (part II). J Pediatr Health Care 2007:21:226-237.

17 Hurth J, Shaw E, Izeman SG, Whaley K, Rogers SJ: Areas of agreement about effective practices among programs serving young children with autism spectrum disorders. Infants Young Child 1999;12:17-26.

18 Logan KR, Bakeman R, Keefe EG: Effects of instructional variables of engaged behavior intervention in a home setting with a children with autism. J Positive Behav Intervent 1997;4:53-60.

19 Rogers SJ: Intervention for young children with autism: from research to practice. Infants Young Child 1999;12:1-16.

-20 Myles BS, Grossman BG, Aspy R, Henry SA, Coffin AB: Planning a comprehensive program for students with autism spectrum disorders using evidence-based practices. Educ Train Develop Disabil 2007;42:398-409.

-21 Rizzo A, Buckwater J, Bowerly T, van der Zang C, Humphrey L, Neumann U, Chua C, Kyriakakis C, van Rooyen A, Sisemore D: The virtual classroom: a virtual reality environment for the assessment and rehabilita- tion of attention deficits. Cyberpsychol Behav 2000;3:483-499.

-22 Lovaas OI: Behavioral treatment and normal educational and intellectual functioning in young autistic children. J Consult Clin Psychol 1987;55:3-9.

23 Cromby JJ, Standen PJ, Brown DJ: The potentials of virtual environments in the education and training of people with learning disabilities. J Intellect Disabil Res 1996; 40:489-501

24 Howlin P: Practitioner review: psychological and educational treatments for autism. J Child Psychol Psychiatry 1998;39:307-322.

$\checkmark 25$ Iovannone R, Dunlap G, Huber H, Kincaid D: Effective educational practices for students with autism spectrum disorders. Foc Autism Other Develop Disabil 2003;18:150165.

26 Anttila H, Autti-Ramo I, Suoranta J, Makela M, Malmivaara A: Effectiveness of physical therapy interventions for children with cerebral palsy: a systematic review. BMC Pediatr 2008;8:14.

27 Neisser U: What are the important questions? in Gruneberg MM, Morris PE, Sykes RN (eds): Practical Aspects of Memory. London, Academic Press, 1978, pp 3-24.

28 Strickland D, McAllister D, Coles CD, Osborne S: An evolution of virtual reality training designs for children with autism and fetal alcohol spectrum disorders. Top Lang Disord 2007;27:226-241.

29 Weiss MJ: Skill acquisition, direct instruc tion, and educational curricula; in Luiselli JK, Russo DC, Christian WP, Wilczynski SM (eds): Effective practices for children with autism. Toronto, Oxford University Press, 2008, pp 195-212.

30 Reid D: Benefits of a virtual play rehabilitation environment for children with cerebral palsy on perceptions of self-efficacy: a pilot study. Pediatr Rehabil 2005;5:141-148.

31 Cho B-H, Ku J, Jang DP, Kim S, Lee YH, Kim IY, Lee JH, Kim SI: The effect of virtual reality cognitive training for attention enhancement. Cyberpsychol Behav 2002;5:129-137.

32 Cho B-H, Ku J, Jang DP, Kim S, Lee YH, Kim IY, Lee JH, Kim SI: The effect of virtual reality cognitive training for attention enhancement. Cyberpsychol Behav 2002;5:129-137.

33 Othmer S, Kaiser D: Implementation of virtual reality in EEG biofeedback. Cyberpsychol Behav 2000;3:415-420.

34 Yan N, Wang J, Liu M, Zong L, Jiao Y, Yue J, Lv Y, Yang Q, Lan H, Liu Z: Designing a brain-computer interface device for neurofeedback using virtual environments. J Med Biol Eng 2008;28:167-172.

35 Bauminger N, Gal E, Goren-Bar D (eds): Enhancing social communication in highfunctioning children with autism through a co-located interface. 6th Int Workshop on Social Intelligence Design, Trento, 2007.

36 Herrera G, Alcantud F, Jordan R, Blanquer A, Labajo A, De pablo C: Development of symbolic play through the use of virtual real- ity tools in children with autistic spectrum disorders. Autism 2008;12:143-157.

37 Mitchell P, Parsons S, Leonard A: Using virtual environments for teaching social understanding to 6 adolescents with autistic spectrum disorders. J Autism Dev Disord 2007; 37:589-600.

38 Chen Y-P, Kang L-J, Chuang T-Y, Doong J-L, Lee S-J, Tsai M-W, Jeng S-F, Sung W-H: Use of virtual reality to improve upper-extremity control in children with cerebral palsy: a single-subject design. Phys Ther 2007;87:14411457.

39 Fluet GG, Qiu Q, Ramirez D, Adamovich S, Kelly D, Parikh H: Robot-assisted virtual rehabilitation (NJIT-RAVR) system for children with upper extremity hemiplegia. IEEE, 2009.

40 Huber M, Rabin B, Docan C, Burdea G, Nwosu ME, Abdelbaky M, Golomb MR: Playstation 3-based tele-rehabilitation for children with hemiplegia. IEEE, 2008

41 Golomb MR, Barkat-Masih M, Rabin B, Abdelbaky M, Huber M, Burdea G: Eleven months of home virtual reality telerehabilitation - lessons learned. IEEE, 2009.

42 Li W, Lam-Damji S, Chau T, Fehlings D: The development of a home-based virtual reality therapy system to promote upper extremity movement for children with hemiplegic cerebral palsy. Technol Disabil 2009;21:107113.

-43 Jannick MJA, van der Wilden GJ, Navis DW, Visser G, Gussinklo J, Ijzerman M: A lowcost video game applied for training of upper extremity function in children with cerebral palsy: a pilot study. Cyberpsychol Behav 2008;11:27-32.

44 Odle BM, Irving A, Foulds R: Usability of an adaptable video game platform for children with cerebral palsy. IEEE, 2009.

45 Reid D: The use of virtual reality to improve upper-extremity efficiency skills in children with cerebral palsy: a pilot study. Technol Disabil 2002;14:53-61.

46 You SH, Jang SH, Kim Y-H, Kwon Y-H, Barrow I, Hallet M: Cortical reorganization induced by virtual reality therapy in a child with hemiparetic cerebral palsy. Dev Med Child Neurol 2005;47:628-635.

-47 Brutsch K, Schuler T, Koenig A, Zimmerli L, Merillat S, Lunenburger L, Riener R, Jancke L, Meyer-Heim A: Influence of virtual reality soccer game on walking performance in robotic assisted gait training for children. J Neuroeng Rehabilitation 2010;7:15.

48 Bryanton C, Bosse J, Brien M, Mclean J, McCormick A, Sveistrup H: Feasibility, motivation, and selective motor control: virtual reality compared to convention home exercise in children with cerebral palsy. Cyberpsychol Beh 2006;9:123-128.

49 Deutsch JE, Borbely M, Filler J, Huhn K, Guarrera-Bowlby P: Use of a low-cost, commercially available gaming console (Wii) for rehabilitation of an adolescent with cerebral palsy. Phys Ther 2008;88:1196-1207. 
50 Kott KM, Lesher K, DeLeo G: Combining a virtual reality system with treadmill training for children with cerebral palsy. J Cyberther Rehabil 2009;2:35-42.

51 Reid D: Changes in seated postural control in children with cerebral palsy following a virtual play environment intervention: a pilot study. Israel J Occup Ther 2002;11:E75E95.

52 Smith A: The Symbol Digit Modality Test Manual. Los Angeles, Western Psychological Services, 1982

53 Leark RA, Dupuy TR, Greenberg LM, Corman CL, Kindschi CL: TOVA: Professional manual (Version 7.0). Los Alamitos, Universal Attention Disorders, 1996.

54 Seckler P, Burns W, Sandford J: A reliability study of IVA: intermediate visual and auditory continuous performance test. Annu Conv CHADD, 1995.

-55 Dodd KJ, Foley S: Partial body-weight supported treadmill training can improve walking in children with cerebral palsy: a clinical controlled trial. Dev Med Child Neurol 2007; 49:101-105.

56 Held SL, Kott KM, Young B: Standardized Walking Obstacle Course (SWOC): reliability and validity of a functional measurement tool in children who are developing typically and atypically. Pediatr Phys Ther 2006;18: 23-30.

57 Russell DJ, Rosenbaum PL, Avery LM: Gross Motor Function Measure (GMFM-88 \& GMFM-66) User's Manual. London, Cambridge University Press, 2002, pp 42-143.

58 Schindl MR, Forstner C, Kern H: Treadmill training with partial body weight support in nonambulatory patients with cerebral palsy. Arch Phys Med Rehabil 2000;81:301-306.
59 Arns M, de Ridder S, Strehl U, Breteler M, Coenen A: Efficacy of neurofeedback treatment in ADHD: the effects on inattention, impulsivity and hyperactivity: a meta-analysis. Clin EEG Neurosci 2009;40:180-189.

60 Nichols SL, Waschbusch DA: A review of the validity of laboratory cognitive tasks used to assess symptoms of ADHD. Child Psychiatry Hum Dev 2004;34:297-315.

61 Wang M, Reid D: The virtual reality-cognitive rehabilitation (VR-CR) approach for children with autism. J Cyberther Rehabil 2009;2:95-102.

62 De Matteo C, Law M, Russel D, Pollock N, Rosenbaum P, Walter S: QUEST: Quality of Upper Extremity Test. Hamilton, McMaster University, Neurodevelopmental Clinical Research Unit, 1992.

63 Bruininks RH: Bruininks-Oseretsky Test of Motor Proficiency - Owner's Manual. Circle Pines, American Guidance Service, 1978.

64 Reid D: Sitting Assessment for Children with Neuromotor Dysfunction: Administration Manual. San Antonio, Therapy Skill Builders, 1998.

65 van der Lee JH, Beckerman H, Knol DL, de Vet HC, Bouter LM: Clinimetric properties of the motor activity log for the assessment of arm use in hemiparetic patients. Stroke 2004;35:1410-1414.

66 Fugl-Meyer AR, Jaasko I, Leyman I, Olsson S, Steglind S: The post-stroke hemiplegic patient: a method for evaluation of physical performance. Scand J Rehabil Med 1975;7: 104-122.

67 Liepert J, Bauder H, Miltner WH, Taub E, Weiller C: Treatment-induced cortical reorganization after stroke in humans. Stroke 2000;31:1210-1216.

68 Randall M, Johnson L, Reddihough D: The Melbourne Assessment of Unilateral Upper Limb Function: Test Administration Manual. Melbourne, Australia, 1999.
69 Lowe M, Costello AJ: Manual for the Symbolic Play Test. Windsor: NFER, 1976.

70 Lewis V, Boucher J: The Test of Pretend Play: Manual. London, Psychological Corporation, 1997.

71 DiSalvo DA, Oswald DP: Peer-mediated interventions to increase the social interaction of children with autism: consideration of peer experiences. Foc Autism Other Dev Disabil 2002;17:198-208.

72 Folio R, Fewell R: Peabody Developmental Motor Scales (II). Austin, Pro-Ed Publisher, 2000.

73 Jebsen RH, Taylor N, Trieschmann RB, Trotter MJ, Howard LA: An objective and standardized test of hand function. Arch Phys Med Rehabil 1969;50:311-319.

74 Salmeron PA: Childhood and adolescent attention-deficit hyperactivity disorder: diagnosis, clinical practice guidelines, and social implications. J Am Acad Nurse Pract 2009; 21:488-497.

75 Hill EL: Evaluating the theory of executive dysfunction. Dev Rev 2004;24:189-233.

76 Straub K, Obrzut JE: Effects of cerebral palsy on neuropsychological function. J Dev Phys Disabil 2009;21:153-167.

77 Akhutina T, Foreman N, Krichevets A, Matikka L, Narhi V, Pylaeva N, Vahakuopus $\mathrm{J}$ : Improving spatial functioning in children with cerebral palsy using computerized and traditional game tasks. Disabil Rehabil 2003; 25:1361-1371.

78 Odom S, Brown W, Frey T, Karasu N, SmithCanter L, Strain P: Evidence-based practices for young children with autism: contributions from single-subject research. Foc Autism Other Dev Disabil 2003; 18:166-175. 